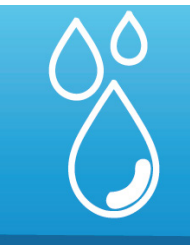

HEMATOLOGY
Department of Immunohematology and Blood Transfusion, Kasturba Medical College, Manipal, Manipal Academy of Higher Education, Manipal, Karnataka, India
DOI: $10.15386 / \mathrm{mpr}-1954$

Manuscript received: 03.11.2020 Received in revised form: 24.07.2021 Accepted: 22.08.2021

Address for correspondence:

shameeshastry@gmail.com

This work is licensed under a Creative Commons Attribution-NonCommercialNoDerivatives 4.0 International License

\title{
The role of thrombocytapheresis in the management of extreme thrombocytosis: a 6 years' experience from a tertiary care center
}

Deepika Chenna, Isha Polavarapu, Dhivya Kandasamy, Ganesh Mohan, Shamee Shastry

\begin{abstract}
Background. According to the American Society for Apheresis (ASFA) guidelines, thrombocytapheresis is a Category II indication in symptomatic patients and is a Category III indication when used as secondary or prophylactic treatment. The role of thrombocytapheresis is to prevent untoward complications that might occur even before the cytoreductive agents can exert their action.

Methods. A retrospective analysis of patients who underwent thrombocytapheresis between 2012 to 2018 was conducted. Demographic details, complete blood counts, diagnosis and indication for thrombocytapheresis were noted.

Results. A total of 12 patients with thrombocytosis were included in the study. The cause of thrombocytosis was primary in $3(25 \%)$ patients and secondary in $9(75 \%)$ patients. The average percentage reduction in platelet count was $47.1 \%$ (range $12.3 \%-65.64 \%$ ). There was a significant decrease in platelet count, platelet crit, and mean platelet volume after the procedure when compared to pre-procedure.

Conclusion. Thrombocytapheresis selectively reduces platelet counts with no effect on other cellular and plasma components. The role of thrombocytapheresis in extreme thrombocytosis is to be considered for an immediate decrease in platelet count and to minimize the risks associated with thrombocytosis.
\end{abstract}

Keywords: platelets, thrombocytosis, thrombocytapheresis, apheresis

\section{Introduction}

Thrombocytosis is defined as a platelet count $>450 \times 10^{9} / 1$ which can be primary or secondary (reactive). Essential thrombocythemia (ET), a chronic myeloproliferative disorder is characterized by clonal proliferation of megakaryocytes, which is caused by a defect of the early pluripotent or a committed stem cell [1]. These patients may present with both thrombotic and hemorrhagic diathesis [1]. In Reactive Thrombocytosis (RT), the increased platelet count is seen in response to infection, trauma, or surgery where the mechanism of platelet production is varied [2-5]. Although RT is a benign and self-limiting condition in most individuals, extreme thrombocytosis may sometimes lead to late thrombotic complications [6]. According to the American Society for Apheresis (ASFA) guidelines, thrombocytapheresis is a Category II indication with Grade 2C recommendation in symptomatic patients and is a Category III indication with Grade 2C recommendation when used as secondary or prophylactic treatment [7]. The role of thrombocytapheresis is to prevent untoward complications that might occur even before the initiation of action of cytoreductive agents. We discuss our 6 years' experience of performing thrombocytapheresis as a part of management for both primary and secondary thrombocytosis in our center. 


\section{Methods}

We conducted a retrospective observational study between January 2013 to December 2018 on the efficacy of thrombocytapheresis in reducing the platelet counts in patients with thrombocytosis. The data was collected by retrieving the records of therapeutic apheresis procedures. Thrombocytapheresis was performed for patients referred by clinicians to the Department of Transfusion Medicine. The decision for thrombocytapheresis was considered and performed as per ASFA guidelines. The data collected includes demographic details like age, gender and clinical details like diagnosis, cause (primary/ secondary), onset of thrombocytosis, and, presence or absence of any complications. The pre and post procedure hematological parameters like hemoglobin $(\mathrm{Hb})$, platelet counts, mean platelet volume (MPV), platelet crit (Pct), white blood cell (WBC) count of the patients were retrieved from laboratory management system and the percentage decrease in the counts were calculated post thrombocytapheresis. All the procedures were performed using apheresis cell separator COM.TEC ${ }^{\circledR}$ (Fresenius Kabi, India Pvt Ltd, headquartered at Bad Homburg, Germany). The statistical analysis was done using SPSS version 18 (SPSS Inc. Released 2009. PASW Statistics for Windows, Version 18.0. Chicago: SPSS Inc.). Descriptive statistics was used to calculate mean and percentages. Comparison of pre and post procedure hematological parameters was performed using paired ' $t$ ' test.

\section{Results}

During the study period, a total of $12(\mathrm{n}=4$ $(33 \%)$ - female, $n=8(67 \%)-$ male) patients underwent thrombocytapheresis procedure. The mean age of the patients was 55 years ranging from 21-68 years. The cause for thrombocytosis was primary in $3(25 \%)$ and secondary in $9(75 \%)$ of the patients who underwent thrombocytapheresis. The most common sensitizing event for reactive thrombocytosis was surgery, as shown in table I). Most of the patients (75\%) had a good reduction in platelet count with a single procedure. The average percentage reduction in platelet count was $47.1 \%$ (range 12.3\%-65.64\%). The mean time (in days) taken for rise in platelet count following the sensitizing event in reactive thrombocytosis was 6.2 days. The mean preprocedure platelet count and the platelet crit (Pct) were $1520 \times 10^{3} / \mu \mathrm{L}$ (range $946 \times 10^{3} / \mu \mathrm{L}-2288 \times 10^{3} / \mu \mathrm{L}$ ) 0.908 respectively. The clinical profile of patients who underwent thrombocytapheresis is shown in table II. On comparison of pre and post procedure hematological parameters, there was a significant decrease in platelet count, Pct and MPV and no significant difference in hemoglobin and hematocrit. as only concentrated platelets were removed by apheresis procedure (Table III). The clinical course of one patient who developed reactive thrombocytosis following coronary artery bypass graft (CABG) surgery is depicted in figure 1 and the hematological parameters before and after thrombocytapheresis for patients with reactive thrombocytosis is depicted in figure 2 .
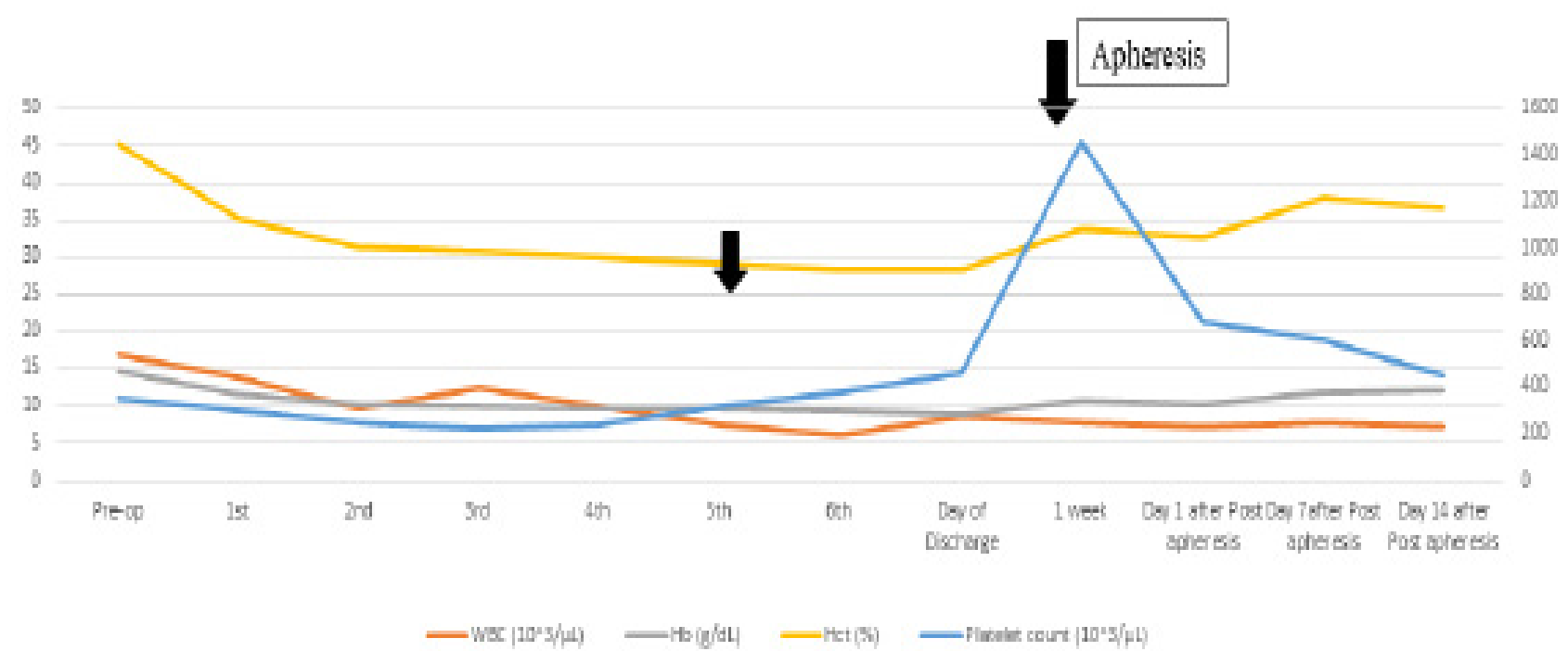

Figure 1. Clinical course of a patient who developed reactive thrombocytosis. 
Table I. Patients who underwent thrombocytapheresis during the study.

\begin{tabular}{|c|c|c|c|}
\hline Sno & Diagnosis & $\begin{array}{c}\text { Number of } \\
\text { Patients }\end{array}$ & $\begin{array}{l}\text { Number of } \\
\text { Procedure }\end{array}$ \\
\hline 1 & Essential thrombocythemia & 1 & 1 \\
\hline 2 & Post coronary artery bypass grafting surgery & 5 & 6 \\
\hline 3 & Chronic myeloid leukemia with accelerated phase \& thrombocythemia & 1 & 3 \\
\hline 4 & Polycythemia vera Jak 2 positive & 1 & 3 \\
\hline 5 & Post splenectomy & 1 & 1 \\
\hline 6 & Metastastatic adenocarcinoma ovary- post neo adjuvant chemotherapy & 1 & 1 \\
\hline 7 & Reactive thrombocytosis post debridement of left lower limb necrotizing fascitis & 1 & 1 \\
\hline 8 & Road traffic accident with subdural hematoma & 1 & 1 \\
\hline
\end{tabular}

Table II. Clinical profile of patients who underwent therapeutic thrombocytapheresis.

\begin{tabular}{|c|c|c|c|c|c|c|c|c|c|c|c|}
\hline \multirow[t]{2}{*}{ Sno } & \multirow{2}{*}{$\begin{array}{l}\text { Age } \\
\text { (years)/ } \\
\text { Gender }\end{array}$} & \multirow[t]{2}{*}{ Diagnosis } & \multirow{2}{*}{$\begin{array}{l}\text { Primary/ } \\
\text { Secondary }\end{array}$} & \multirow{2}{*}{$\begin{array}{l}\text { Prophylactic/ } \\
\text { Therapeutic }\end{array}$} & \multicolumn{2}{|c|}{$\begin{array}{l}\text { Hemoglobin } \\
\text { (g/dL) }\end{array}$} & \multicolumn{2}{|c|}{$\begin{array}{l}\text { Platelet count } \\
\left(\times 10^{3} / \mu \mathrm{L}\right)\end{array}$} & \multicolumn{2}{|c|}{$\begin{array}{l}\text { WBC count } \\
\left(\times 10^{3} / \mu \mathrm{L}\right)\end{array}$} & \multirow{2}{*}{\begin{tabular}{|c|}
$\begin{array}{c}\text { No. of } \\
\text { procedures }\end{array}$ \\
1
\end{tabular}} \\
\hline & & & & & Pre & Post & Pre & Post & Pre & Post & \\
\hline 1 & $49 / \mathrm{F}$ & $\begin{array}{l}\text { Metastatic adenocarcinoma } \\
\text { ovary - post neo adjuvant } \\
\text { chemotherapy }\end{array}$ & Secondary & Prophylactic & 10.6 & 9.5 & 1016 & 436 & 27.1 & 11.9 & 1 \\
\hline 2 & $54 / \mathrm{M}$ & $\begin{array}{l}\text { Post splenectomy due to } \\
\text { blunt abdominal trauma }\end{array}$ & Secondary & Prophylactic & 10.8 & 11 & 1539 & 538 & 10.3 & 10.8 & 1 \\
\hline 3 & $52 / \mathrm{F}$ & $\begin{array}{l}\text { Essential thrombocytosis } \\
\text { (incidental finding), JAK } 2 \\
\text { positive }\end{array}$ & Primary & Prophylactic & 9.2 & 9.7 & 2288 & 1337 & 34.9 & 35.3 & 1 \\
\hline 4 & $56 / \mathrm{M}$ & $\begin{array}{l}\text { Post CABG reactive } \\
\text { thrombocytosis }\end{array}$ & Secondary & Prophylactic & 13.4 & 13.1 & 1167 & 595 & 18.8 & 12.8 & 1 \\
\hline 5 & $65 / \mathrm{M}$ & $\begin{array}{l}\text { Post CABG reactive } \\
\text { thrombocytosis }\end{array}$ & Secondary & Prophylactic & 10.5 & 10 & 946 & 325 & 15.3 & 13.1 & 1 \\
\hline 6 & $62 / \mathrm{M}$ & $\begin{array}{l}\text { Post CABG reactive } \\
\text { thrombocytosis }\end{array}$ & Secondary & Prophylactic & 12.6 & 12.9 & 988 & 480 & 11.1 & 11.3 & 1 \\
\hline 7 & $72 / \mathrm{M}$ & $\begin{array}{l}\text { CML with accelerated } \\
\text { phase \& thrombocythemia }\end{array}$ & Primary & Prophylactic & 8.3 & 8 & 2282 & 1804 & - & - & 3 \\
\hline 8 & $42 / \mathrm{F}$ & $\begin{array}{l}\text { Necrotizing fascitis of } \\
\text { left lower limb reactive } \\
\text { thrombocytosis }\end{array}$ & Secondary & Therapeutic & 10.2 & 9.2 & 1218 & 319 & 10.9 & 8.1 & 1 \\
\hline 9 & $59 / \mathrm{M}$ & $\begin{array}{l}\text { Post CABG reactive } \\
\text { thrombocytosis }\end{array}$ & Secondary & Prophylactic & 11 & 10.9 & 1253 & 502 & 17.7 & 13.9 & 2 \\
\hline 10 & $68 / \mathrm{M}$ & $\begin{array}{l}\text { Post CABG reactive } \\
\text { thrombocytosis }\end{array}$ & Secondary & Prophylactic & 10.8 & 10.8 & 1454 & 788 & - & - & 1 \\
\hline 11 & $65 / \mathrm{M}$ & $\begin{array}{l}\text { Polycythemia vera Jak } 2 \\
\text { positive }\end{array}$ & Primary & Prophylactic & - & - & 2087 & 804 & - & - & 3 \\
\hline 12 & $21 / \mathrm{F}$ & Subdural hematoma & Secondary & Prophylactic & 10.9 & 10.8 & 1060 & 373 & 20.7 & 16.6 & 1 \\
\hline
\end{tabular}

Table III. Hematological indices before and after thrombocytapheresis.

\begin{tabular}{|c|c|c|c|c|c|c|}
\hline \multirow{2}{*}{ Hematological Parameters } & \multirow{2}{*}{$\mathbf{N}$} & \multicolumn{2}{|c|}{ Pre } & \multicolumn{2}{|c|}{ Post } & \multirow{2}{*}{ P-value } \\
\hline & & Mean & SD & Mean & SD & \\
\hline Hemoglobin $(g / d L))$ & 12 & 10.93 & 1.09 & 10.77 & 1.20 & 0.282 \\
\hline Hematocrit $(\%)$ & 12 & 33.75 & 3.31 & 33.63 & 3.78 & 0.776 \\
\hline White blood cell count $\left(\times 10^{3} / \mu \mathrm{L}\right)$ & 11 & 18.21 & 7.38 & 15.15 & 7.21 & 0.053 \\
\hline Mean platelet volume (fL) & 12 & 7.20 & 0.82 & 7.00 & 0.74 & 0.009 \\
\hline Platelet crit (\%) & 12 & 0.91 & 0.38 & 0.44 & 0.26 & $<0.001$ \\
\hline Platelet count $\left(\times 10^{3} / \mu \mathrm{L}\right)$ & 18 & 1520.22 & 452.34 & 898.28 & 536.59 & $<0.001$ \\
\hline
\end{tabular}




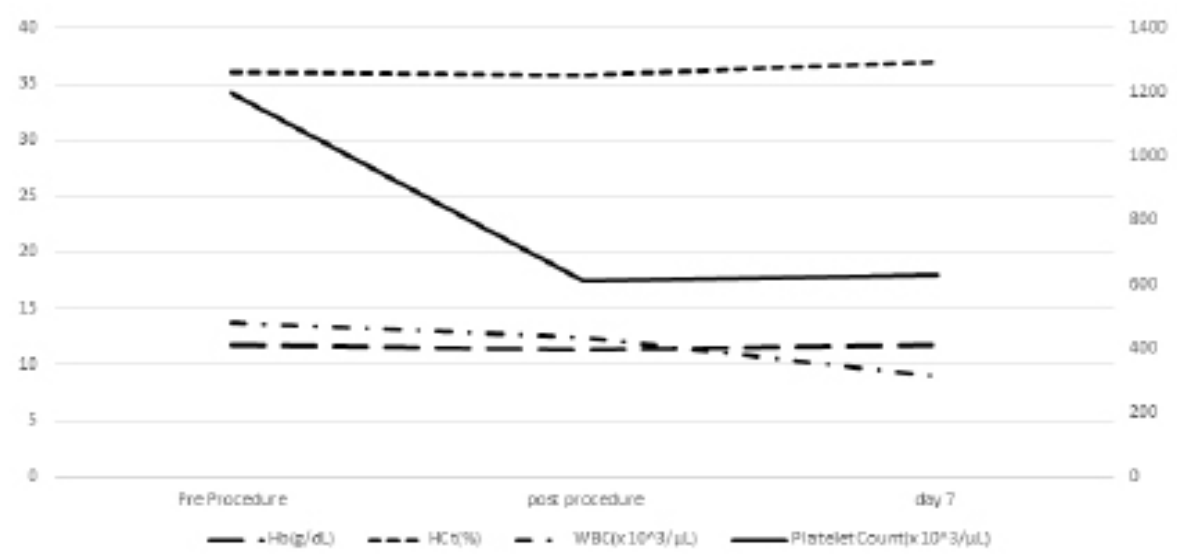

Figure 2. Haematological parameters before, after and 7 days follow up in reactive thrombocytosis.

\section{Discussion}

Thrombocytosis can be an incidental finding in most patients or it might present with complications. The cause for thrombocytosis can be classified as clonal, reactive and spurious [6]. Whenever, there is a suspected thrombocytosis measured by automated cell counters, the counts are to be confirmed by peripheral blood smear evaluation to preclude the causes of spurious thrombocytosis like cryoglobulin crystals, red blood cell microvesicles etc [6]. Thrombocytosis can be a sequel of decreased or absent pooling of platelets post splenectomy or due to an increased production. Increased production in primary thrombocytosis is due to activating mutations in the gene of JAK2, MPL, and calreticulin and in secondary thrombocytosis it is associated with increased levels of thrombopoietic growth factors like Thrombopoietin, Interleukin 6 etc. [8]. Patients with thrombocytosis are at risk of both thrombotic and hemorrhagic complications. The risk of thrombosis is not merely associated with increased platelet count but because of the presence of hyper reactive platelets. Apart from myeloproliferative neoplasms these hyper reactive platelets are found in chronic inflammation, neoplasia, iron deficiency and exposure to high altitude [8]. As per ASFA guidelines, indication for thrombocytapheresis is a category II; grade $2 \mathrm{C}$ recommendation for symptomatic patients and Category III; grade $2 \mathrm{C}$ recommendation for prophylactic/ secondary thrombocytosis patients [7].

Thrombocytapheresis selectively reduces platelet counts with no effect on other cellular and plasma components. This is evident from the current study where there is a significant decrease in platelet count, PCT,
MPV and WBC but not in hemoglobin $(\mathrm{Hb})$ content and hematocrit. However, other researchers have reported a significant decrease in $\mathrm{Hb}$ content, along with WBC and platelet counts [9]. Modern intermittent-flow and continuous-flow automated centrifugation systems are effective means of rapidly and effectively reducing platelet counts. Single needle access procedures are equivalent in efficacy and quality to dual needle plateletpheresis protocols. About 1.5-2 times the total blood volume is generally processed, which can reduce platelet counts by as much as $30-60 \%$. Apheresis sessions should be continued until platelet counts drop to below $600 \times 10^{9} / \mathrm{L}$ or until symptom alleviation and resolution of clinical indications for treatment [10].

The risk associated with complications of thrombocytosis due to primary and secondary causes was studied in earlier years. A cohort of people having thrombocytosis were followed up in these studies for complications with a population size ranging from 129-2000. The proportion of subjects with primary thrombocytosis (0-89) was much less compared to that of secondary thrombocytosis (57-1934). The thrombotic and hemorrhagic risks associated with primary thrombocytosis ranged from 3.8 to $23.7 \%$ and $23.7 \%$ to $36 \%$ while in secondary thrombocytosis it was ranging from 0 to $14 \%$ and 3.03 to $4 \%$ respectively [2,11-15]. Though it is evident from the above studies that the percentage of population developing risks was comparatively lower in the reactive thrombocytosis group when compared to primary thrombocytosis, this needs to be re-explored in the coming days as the number of reports highlighting the risks associated with secondary thrombocytosis are increasing [16-23]. 
The incidence of thrombotic episodes ranged from $22 \%$ to $63 \%$ and the incidence of bleeding episodes from $11 \%$ to $21 \%$ in patients with thrombocythemia [24]. In our study, thrombocytapheresis was performed as a prophylactic procedure for all the patients except for one who was symptomatic and it was performed therapeutically. Thrombocytapheresis was considered in these patients to prevent untoward bleeding and or thrombotic complications. First line of treatment for ET is hydroxyurea and second line of treatment anagrelide and busulfan which act by suppressing the bone marrow production of blood cells including platelets [24]. In a recent review, it is proposed to consider thrombocytapheresis in the management of thrombocytosis in myeloproliferative neoplasms based on the clinical scenario, degree of thrombocytosis and the patient's risk profile [10].

RT is not always innocuous as stated before. It might lead to a prothrombotic state, resulting in risk of thromboembolism [25]. A prospective study on 147 patients who underwent splenectomy, $14.3 \%$ patients with reactive thrombocytosis developed portal, mesenteric or splenic vein thrombosis compared to those without reactive thrombocytosis [26]. RT in critically ill patients was associated with an increased in vitro thrombotic tendency and platelet counts had a relatively linear dose-related relationship with the strength of thrombotic tendency when measured by a thromboelastograph (Pearson's correlation coefficient $=0.53, \mathrm{P}<0.001$ ) [27]

In a recent study, an attempt was made to characterize the rate of thrombotic complications of thrombocytosis in iron deficiency anemia (IDA) over a 40 year period on over 6 million population and a two-fold increased risk of thrombosis in patients with IDA and thrombocytosis (15.8\%) compared to IDA alone $(7.8 \%)$ was observed [28]. In a retrospective analysis of thrombocytosis in critically ill patients, thromboembolism was observed in $13.4 \%$ of subjects and they concluded that thrombocytosis was associated with higher rate of complications in critically ill individuals [29]. The role of prophylactic thrombocytapheresis is to be considered in patients with reactive thrombocytosis. Though the level of evidence does not strongly support prophylactic thrombocytapheresis for patients with reactive thrombocytosis, considering the above studies, randomized controlled trials should be conducted to reevaluate its potential benefits in patient care.

\section{Limitation}

Not all the patients who had thrombocytosis during the study period were evaluated. This would have helped us better understand the effectiveness of thrombocytapheresis procedure in these patients in preventing complications of thrombocytosis.

\section{Conclusion}

The role of thrombocytapheresis in extreme thrombocytosis is to be considered for immediate decrease in platelet count to minimize the risks associated with thrombocytosis. Randomized controlled trials are necessary to establish the benefit of thrombocytapheresis antecedent to cytoreductive therapy in preventing thrombotic or hemorrhagic complications.

\section{References}

1. Tefferi A, Murphy S. Current opinion in essential thrombocythemia: pathogenesis, diagnosis, and management. Blood Rev. 2001;15:121-131.

2. Griesshammer $M$, Bangerter $M$, Sauer $T$, Wennauer R, Bergmann L, Heimpel H. Aetiology and clinical significance of thrombocytosis: analysis of 732 patients with an elevated platelet count. J Intern Med. 1999;245:295-300.

3. Folman CC, Ooms M, Kuenen BB, de Jong SM, Vet RJ, de Haas $\mathrm{M}$, et al. The role of thrombopoietin in post-operative thrombocytosis. Br J Hematol. 2001;114:126-133.

4. Schafer AI. Thrombocytosis. N Engl J Med. 2004;350:12111219.

5. Vo QT, Thompson DF. A Review and Assessment of DrugInduced Thrombocytosis. Ann Pharmacother. 2019;53:523-536.

6. Bleeker JS, Hogan WJ. Thrombocytosis: diagnostic evaluation, thrombotic risk stratification, and risk-based management strategies. Thrombosis. 2011;2011:536062.

7. Schwartz J, Padmanabhan A, Aqui N, Balogun RA, Connelly-Smith L, Delaney M, et al. Guidelines on the Use of Therapeutic Apheresis in Clinical Practice-EvidenceBased Approach from the Writing Committee of the American Society for Apheresis: The Seventh Special Issue. J Clin Apher. 2010;31:149-162.

8. Scharf RE. Do we need antiplatelet therapy in thrombocytosis? Contra. Proposal for an individualized riskadapted treatment. Hamostaseologie. 2016;36:241-260.

9. Prakash S, Hans R, Sharma RR, Malhotra P, Marwaha N. Therapeutic Thrombocytapheresis for Symptomatic Thrombocytosis in Hemato-Oncology Patients. Ther Apher Dial. 2018;22:93-95.

10. Boddu P, Falchi L, Hosing C, Newberry K, Bose P, Verstovsek $\mathrm{S}$. The role of thrombocytapheresis in the contemporary management of hyperthrombocytosis in myeloproliferative neoplasms: A case-based review. Leuk Res. 2017;58:14-22.

11. Buss DH, Stuart JJ, Lipscomb GE. The incidence of thrombotic and hemorrhagic disorders in association with extreme thrombocytosis: an analysis of 129 cases. Am J Hematol. 1985;20:365-372.

12. Buss DH, Cashell AW, O'Connor ML, Richards F 2nd, Case LD. Occurence, etiology, and clinical significance of extreme thrombocytosis: a study of 280 cases. Am J Med. 1994;96:247-253.

13. Yohannan MD, Higgy KE, al-Mashhadani SA, Santhoshkumar CR. Thrombocytosis. Etiologic analysis of 663 patients. Clin Pediatr (Phila). 1994;33:340-343. 
14. Santhosh-Kumar CR, Yohannan MD, Higgy KE, alMashhadani SA. Thrombocytosis in adults: analysis of 777 patients. J Intern Med. 1991;229:493-495.

15. Aydogan T, Kanbay M, Alici O, Kosar A. Incidence and etiology of thrombocytosis in an adult Turkish population. Platelets. 2006; 17:328-331.

16. Raso S, Napolitano M, Saccullo G, Siragusa S. Abdominal aortic thrombosis secondary to reactive thrombocytosis in a patient with iron deficiency anemia. Ann Hematol. 2016;95:1389-1390.

17. Geng Y, Chen Z, Dai L, Liu G, He X. Recurrent arterial thrombosis of the lower extremity with secondary thrombocythemia due to reperfusion injury: a case report. Ann Palliat Med. 2020;9:3690-3697.

18. Xiang $\mathrm{T}$, Cheng $\mathrm{M}$. Enoxaparin-induced reactive thrombocytosis : a case report. Thromb J. 2021;19:34.

19. Kalantri P, Kaushik A, Singla R, Bade A, Bansal NO. Reactive thrombocytosis leading to stent thrombosis. J Pract Cardiovasc Sci. 2020;6:180-183.

20. Mangwana S. Thrombocytapheresis: An important therapeutic tool in the management of thrombocytosis in cerebral venous thrombosis. Int $\mathrm{J}$ Blood Transfus Immunohematol. 2020;10:100054Z02SM2020.

21. Sarbay H, Akbayram S. Secondary severe thrombocytosis in a patient who underwent splenectomy due to hereditary spherocytosis and its treatment using hydroxyurea. Pan Afr Med J. 2019;32:175.

22. Martínez RC, Quaynor S, Alkhalifah M, Goldenberg FD. Plateletpheresis: Nonoperative Management of Symptomatic Carotid Thrombosis in a Patient with Reactive
Thrombocytosis. World Neurosurg. 2018;114:126-129.

23. Tarabishy SP, Inglesby D, Tapp M, Corral GD, Herrera FA. Thrombocytosis is associated with complications after microvascular surgery: An NSQIP data analysis. Microsurgery. 2020;40:288-297.

24. Falchi L, Bose P, Newberry KJ, Verstovsek S. Approach to patients with essential thrombocythemia and very high platelet counts: what is the evidence for treatment? $\mathrm{Br} \mathrm{J}$ Hematol. 2017;176:352-364.

25. Simanek R, Vormittag R, Ay C, Alguel G, Dunkler D, Schwarzinger I, et al. High platelet count associated with venous thromboembolism in cancer patients: results from the Vienna Cancer and Thrombosis Study (CATS). J Thromb Hemost. 2010;8:114-120.

26. Stamou KM, Toutouzas KG, Kekis PB, Nakos S, Gafou A, Manouras A, et al. Prospective study of the incidence and risk factors of postsplenectomy thrombosis of the portal, mesenteric, and splenic veins. Arch Surg. 2006;141:663-669.

27. Duff OC, Ho KM, Maybury SM. In vitro thrombotic tendency of reactive thrombocytosis in critically ill patients: a prospective case-control study. Anaesth Intensive Care. 2012;40:472-478.

28. Song AB, Kuter DJ, Al-Samkari H. Characterization of the rate, predictors, and thrombotic complications of thrombocytosis in iron deficiency anemia. Am J Hematol. 2020;95:1180-1186.

29. Banach M, Lautenschläger C, Kellner P, Soukup J. Etiology and clinical relevance of elevated platelet count in ICU patients: A retrospective analysis. Med Klin Intensivmed Notfmed. 2018;113:101-107. 